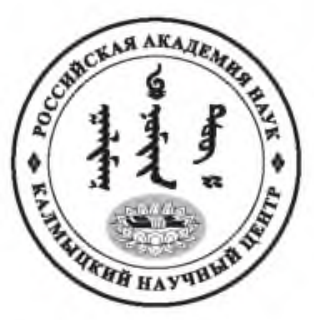

Published in the Russian Federation

Oriental Studies (Previous Name: Bulletin of the Kalmyk Institute

for Humanities of the Russian Academy of Sciences)

Has been issued as a journal since 2008

ISSN: 2619-0990; E-ISSN: 2619-1008

Vol. 14, Is. 2, pp. 384-392, 2021

Journal homepage: https://kigiran.elpub.ru

УДК / UDC 82-31

DOI: $10.22162 / 2619-0990-2021-54-2-384-392$

\title{
Персонажная система и мотивная структура повести Г. Башкуева «Убить время»
}

\section{Ольга Владимировна Хандарова}

\author{
${ }^{1}$ Институт монголоведения, буддологии и тибетологии СО РАН (д. 6. ул. Сахьяновой, 670047 \\ Улан-Удэ, Российская Федерация) \\ кандидат филологических наук, младший научный сотрудник \\ 0000-0001-5573-1888. E-mail: olga.khandarova@atmail.ru \\ (C) КалмНІ РАН, 2021 \\ (C) Хандарова О. В., 2021
}

\begin{abstract}
Аннотация. Введение. В творчестве Геннадия Тарасовича Башкуева происходит осмысление позднесоветской и постсоветской эпох, одним из значимых прозаических произведений писателя является повесть «Убить время». Цель исследования - выявление и анализ связи между системой персонажей повести и ее мотивной структурой, что помогает прояснить замысел эклектичного по структуре произведения, близкого по форме к циклу рассказов. Мапериалы и методы. Материалом исследования послужила повесть Г. Т. Башкуева «Убить время», При анализе произведения автор данной статьи опирается на положения о связи семантики мотива и персонажа, о предикативности мотива, а также на концепции мотивных комплексов и лейтмотивного построения повествования. Результаmы. Главный персонаж повести - рассказчик, содержание повести делится на воспоминания о детстве и воспоминания о недавнем прошлом. Персонажей детства можно поделить на три группы: семья, друзья, взрослые - с ними связаны мотивы счастья, праздника, романтической мечты и мотив утраты. Персонажи взрослой жизни - друзья детства и женщины, с которыми связываются мотивы маргинального быта, измены, вины, предательства и мотив романтики. Мотивы «детской» и «взрослой» частей воспоминаний переплетаются, именно мотивная структура обеспечивает цельность произведения. Ключевую роль в повести играет сдвоенный образ - продавщицы Инги и городской сумасшедшей, объединяющий две основные темы рефлексии рассказчика: детство и женщины. Сюжетная структура повести отчасти укладывается в универсальную мифологическую схему: череда испытаний - зарисовок-событий из жизни автобиографического рассказчика - выстраивается в свособразное «мифологическое путешествие» и заканчивается обретением «эликсира» - катарсиса и духовного освобождения. Bыводы. Образ главного героя, рассказчика, эксплицирован в тексте и раскрывается в системе мотивов, связанных с персонажами его воспоминаний. Анали'з системы персонажсй позволяет выявить ключевые идеи повести, а также произвести трактовку ее заглавия. Фокусом авторской точки зрения, объединяющим, на первый взгляд, разрозненные истории, становится рефлексия по поводу времени.
\end{abstract}


Ключевые слова: литература Бурятии, Г. Т. Башкуев, система персонажей, мотивная структура, мотивный комплекс, литературный характер, образ рассказчика

Благодарность. Статья подготовлена в рамках государственного задания (проект XII.192.1.4. «Миф и история в фольклоре и литературе бурят и русских сибиряков: универсалии и специфика». Номер госрегистрации: АAАA-A17-117021310268-2).

Для цитирования: Хандарова О. В. Персонажная система и мотивная структура повести Г. Башкуева «Убить время» // Oriental Studies. 2021. T. 14. № 2. С. 384-392. DOI: 10.22162/26190990-2021-54-2-384-392

\title{
To Kill Time by G. Bashkuev: Character System and Motif Structure of the Novel Revisited
}

\author{
Olga V. Khandarova
}

${ }^{1}$ Institute for Mongolian, Buddhist and Tibetan Studies, Siberian Branch of the RAS (6, Sakhyanova St., 670047 Ulan-Ude, Russian Federation)

Cand. Sc. (Philology), Junior Research Associate

0000-0001-5573-1888. E-mail: olga.khandarova $(a$ mail.ru

\author{
(C) KalmSC RAS, 2021 \\ (C) Khandarova O. V., 2021
}

\begin{abstract}
Introduction. Gennady Bashkuev's works attempt to comprehend the late Soviet and postSoviet eras, and To Kill Time proves a most significant prose work of the writer. Goals. The article seeks to identify and analyze the relationship between the system of characters in the novel and its motif structure, which helps clarify the underlying idea of the work, eclectic in structure and close in form to a short story cycle. Methods. The study rests on the theses about a relationship between semantics of motif and character, predicativity of motif, and on the concept of motif complexes and leitmotif construction of the narrative. Results. The main character of the novel is the narrator, the narrative proper divided into childhood memories and those of recent past. The characters of childhood can be clustered into three groups: family, friends, adults - motifs of happiness, celebration, romantic dreams and that of loss are associated with them. The characters of adulthood are women and childhood friends who are associated with motifs of marginal life, betrayal, guilt, and that of romance. The motifs of 'childhood' and 'adulthood' memories are intertwined, and it is the motif structure that ensures the integrity of the narrative. The key role in the novel is played by the binary image the saleswoman Inga and the city madwoman - that combines two main themes for the narrator's self-reflection: childhood and women. The plot structure partly fits into the universal mythological scheme: a series of trials - sketches-events from the life of the autobiographical narrator - is built into somewhat a 'mythological journey' to finally end with the acquisition of 'elixir' - catharsis and spiritual liberation. Conclusions. The image of the protagonist, the narrator, is explicated in the text and is revealed in the system of motifs associated with characters of his memories. Analysis of the character system proves instrumental in revealing key ideas of the novel and interpreting its title: those are reflections about time that become a focus of the author's viewpoint uniting the seemingly disparate stories.
\end{abstract}

Keywords: literature of Buryatia, G. T. Bashkuev, character system, motif structure, motif complex. literary character, storyteller's image

Acknowledgements. The article was funded by government assignment — project XII.192.1.4. 'Myth and History in Folklore and Literature of the Buryats and Ethnic Russian Residents of Siberia: Common and Specific Features' (state reg. no. AAAA-A17-117021310268-2).

For citation: Khandarova O. V. To Kill Time by G. Bashkuev: Character System and Motif Structure of the Novel Revisited. Oriental Studies. 2021. Vol. 14 (2): 384-392. (In Russ.). DOI: 10.22162/26190990-2021-54-2-384-392 


\section{Введение}

Геннадий

(г. p. 1954) - русскоязычный бурятский прозаик, драматург, публицист. Г. Т. Башкуев - автор произведений, в которых происходит осмысление «позднесоветского экзистенциального коллапса) [Саблин, Болячевец, Будацыренова 2017: 96]. Создатель литературного характера «пожилой мальчик», аккумулирующего в себе «новое социальное явление» конца XX в. [Башкеева 2018б], - вспомним, что, по замечанию Л. В. Чернец, «...введение в литературу нового самобытного героя (или антигероя) времени, - важнейший критерий оценки творчества писателя) [Чернец 2016а: 83].

Повесть «Убить время» опубликована в 2016 г. в журнале «Байкал», она входит в состав книги прозы писателя, вышедшей в 2019 г. [Башкуев 2019].

«Убить время» - произведение, которому сам автор, по-видимому, отводит достаточно важное место в своем творчестве. Об этом может свидетельствовать возвращение писателя к материалу и его переработка: существует первый вариант произведения, представляющий собой цикл новелл под общим названием «Записки пожилого мальчика» (о разнице в структуре двух вариантов см.: [Башкеева 20186: 62-63]).

Эклектичность повести, составленной из самостоятельных новелл, на первый взгляд объединенных лишь образом рассказчика и некоторыми второстепенными персонажами, подталкивает к мысли обратиться к анализу персонажной системы с позиции выявления ключевых фигур и связанных с ними комплексов мотивов.

\section{Материалы и методы}

Идея эксплицированности структуры мотивов повести в системе ее персонажей базируется на концепции О. М. Фрейденберг о тождественности в структуре произведения совокупности героев («персонажа») и совокупности мотивов («сюжета») [Фрейденберг 1988: 225].

Мотивный комплекс, формируемый вокруг характера «пожилой мальчик», рассматривается как «феномен, характеризу- ющий целостность произведения) [Близняк 2011: 3]. Характер взаимодействия ключевых мотивов повести и композиции произведения анализируется с опорой на положения о предикативной (сюжетогенной) природе мотива [Силантьев 2004: 79]. Кроме того, наблюдаемые мотивные связи в структуре повести позволяют говорить о принципе лейтмотивного построения повествования [Гаспаров 1994: 30].

При рассмотрении взаимосвязи между персонажной системой и мотивной структурой в повести использован системный подход.

Отражение структуры повести в системе персонажей

Повесть состоит из пятнадцати глав-воспоминаний и сквозной новеллы, в которой повествование разворачивается в настоящем времени: рассказчик находится в заключении, где и создает свои заметки-воспоминания.

Описываемые им события относятся к двум периодам: это время детства, отрочества, пришедшееся на 1960-е гг. и жизнь сорокалетнего мужчины в эпоху 1990-х гг. Каждая новелла либо полностью посвяшена эпизоду из детства или из взрослой жизни, либо совмещает в себе воспоминания, относящиеся к обоим периодам, объединенные общим мотивом (мотивами).

Персонажная система повести довольно обширна: более ста персонажей. В рамках каждой отдельной новеллы есть свои главные герои, в сумме таких около тридцати. Есть персонажи, которые объединяют несколько новелл: в одной-двух они являются главными героями, в других - эпизодическими или внесценическими. Однако в контексте всей истории повести главные персонажи новелл становятся второстепенными, и единственным главным героем выступает сам рассказчик. При рассмотрении всех героев в совокупности просматривается возможность группирования персонажей по их связанности с мотивами повести. Условно можно выделить три группы персонажей в воспоминаниях детства и две группы в описании взрослой жизни рассказчика. 


\section{Персонажи детства}

Эпиграф заключает в себе идею возвращения в детство: «Я ребенком из отчего дома ушел, Воротился уже стариком... Милой родины говор звучит, как тогда, У меня ж на висках седина. И соседские дети глядят на меня... Хэ Чжи-чжан. Династия Тан. VII в. н. э.) [Башкуев 2019: 207]. Концепты детства, дома, семьи являются «связующими нитями» всего цикла [Грязнова 2012: $101]$.

Первая группа персонажей - семья рассказчика: мать, отец, дедушка, с ними связаны наиболее светлые страницы повести. В новеллах «Вещь», «Роман с чемоданом» возникает образ счастливой семьи: «Отец шел по правую руку и нес чемодан, мама, смеясь, по левую, и, когда попадалась ледовая дорожка, мы втроем дружно разбегались, и я, держась за руки взрослых и крича от счастья, катился по льду») (курсив наш. - O. Х.) [Башкуев 2019: 256].

В новелле (Вверх по Миссисипи» идиллическая картина деревенского лета, проведенного у дедушки, с собакой, речкой и лошадью. Однако счастье кратковременно и непрочно, оно не выдерживает испытания временем и столкновения с жестоким внешним миром. Окончательно разрушились отношения родителей, и ушел отец: щедрый и яркий человек, словно не признающий аскетизма серой и бедной советской реальности, всегда умевший восхитить сына, удивить жену, побежден буднями и алкоголизмом. Утрата отца - это главная боль рассказчика, не просто расставание с родным человеком, а словно прощание с самим счастьем Образ отца в повести наполнен любовью: даже подкладка отцовского реглана «невыносимо пахнет ушедшим без возврата» [Башкуев 2019: 218], с его фигурой связываются мотивы романтики, праздника. В деревенском раю тоже все закончилось трагически: дедушка слег и умер, и несбыточными оказались его совместные с внуком планы. Мечта о Миссисипи лопается как пузырь от встречи с реальностью.

Образ матери в повести - это вечная хлопотунья, в фартуке поверх платья, всегда занятая бытом, стиркой, глажкой, готовкой. Новая по отношению к предыдущему варианту глава «Селедка под шубой» подсвечивает тему вины, долга перед матерью, вскользь задетую в предыдущих главах. Значимость этой темы в творчестве подтверждается словами самого писателя: «Про греховное и светлое начала в человеке - это ко мне. Я старик, и чего мне теперь стыдиться? Пора каяться. И в первую очередь - перед мамой. Я принес маме немало горя, да и другим людям» [Батудаева 2019]

Все три образа (мать, отец, дедушка) в повести создают антиномию между наличием тепла и любви в детстве и полным их отсутствием в собственной взрослой семье. Воспоминания о свосй семье рассказчик словно намеренно вытесняет на периферию сознания. О сыне упоминается, жену рассказчик обманывает с другими женщинами, испытывает к ней чувство отчуждения и одновременно жалости: «Она сильно уставала, жить с непутевым мужем, знаете ли...» [Башкуев 2019: 282]. Неприкрыто враждебны отношения героя с тещей. На протяжении всей жизни мечта о счастливой семье и счастливых родителях для рассказчика остается единственным спасательным кругом: «по правое весло сидит во всем чистом отец, по левое - мама в новых платье и капроновых чулках, они молча улыбаются мне, седому мальчику, сидящему у руля〉 [Башкуев 2019: 257]. Вторая группа персонажей детства - это друзья мальчика по двору своего рода «товарищи по несчастью», с которыми рассказчик проходит школу жизни. Детство их наполнено подвигами и предательствами, настоящей и фальшивой дружбой, сильными любовными переживаниями и расставаниями. Самые серьезные по накалу страстей, наиболее эмоциональные драмы в повести - детские. Но жизнь беспощадна, и первые сильные и чистые страсти обязательно происходят в самых некрасивых декорациях и непременно заканчиваются огромным разочарованием, к чему постепенно и привыкают все эти дети. Ежегодное утопление дядей Володей щенков дворовой собаки Райны в грязном ведре - словно жуткий символ разрушения детских мечтаний и представлений о жизни, таких же невинных и таких же беспомощных.

Столкновение с реальностью не закаляет и не готовит к настоящей суровой мужской жизни, оно деструктивно и приводит человека к апатии: «Для его художественных произведений более важной темой являет- 
ся позднесоветский экзистенциальный коллапс, резкий контраст между провозглашенными идеалами советской системы и каждодневным опытом алкоголизма, воровства и лжи, переживаемым его героями» [Саблин, Болячевец, Будацыренова 2017: 96]. Дети в прозе Башкуева - это пока еще живые, настоящие люди, которым недолго осталось быть такими, максимум до наступления подросткового возраста, когда они столкнутся с притягивающим и одновременно отвращающим взрослением. А когда проходит и этот период, то жить становится просто скучно, и в зрелом возрасте остается только «убивать время) и печально умирать.

Третья группа персонажей детства - это взрослые, оказавшие сильное влияние на формирование личности рассказчика и замыкающие на себе ключевые мотивы повести.

Продавщица Инга - первая красавица двора, воплощение манящей женской красоты, создаваемой нехитрыми средствами. Ингина история словно задает модель женской судьбы в повести: неудачный роман с ничтожным экспедитором Владиком, его нахальные измены, Ингины скандалы, драки, дрязги, окончательный уход Владика, Ингино унижение в попытках вернуть его По-видимому, именно из очарования Ингой и жалости к ней растет отношение повзрослевшего рассказчика к женщине: с одной стороны, соблазн женской красотой, с другой стороны, комплекс мужской вины перед женщиной.

Дядя Коля - инвалид войны, чистильщик обуви, рассказчика с ним связывает настоящая дружба. Безногая фигура веселого оптимиста внушает мальчику восхищение, и в его представлениях он кто-то не меньше, чем летчик или капитан дальнего плавания. Как настоящий романтический герой, дядя Коля заслуживает любви совершенно нездешней неземной женшины, экзотической птицы. Однако история заканчивается трагически: реальность такова, что инвалид прекрасно осознает невозможность своего счастья, и, несмотря на любовь девушки с глазами серны и ее уговоры ехать $c$ ней домой, в родной город, он резко рвет с ней, а затем постепенно спивается и умирает. Судьба дяди Коли, рассказанная в одной из начальных новелл, объединяет в себе мотив романтики и несбыточной мечты и мотив некрасивого, маргинального быта.
Кочегар дядя Володя, в сущности, инфернальный персонаж: обладатель грязных кирзовых сапожищ, которые оставляли на половицах барака «следы пришельца иных миров», «чумазой, мятой, обросшей будто угольным шлаком физиономии» и прищуренного красного глаза [Башкуев 2019 263]. Он каждый год шантажирует население двора, собирая по рублю, чтобы не топить щенков, и все равно топит их тайком; он же становится виновником проваленной миссии друзей по нападению на капиталистическую Америку. Детали его образа возникают в ключевой момент повести в драке на вокзале. Рассказчик, впервые увидев своего двухметрового соперника, машинально отмечает, что тот чем-то неуловимым напоминает ему кочегара дядю, а удар арматуриной, начавший драку, опаляет спину, как «огнем из кочегарки».

Оглядываясь на детские годы, герой словно ищет в них опоры для себя в настоящем. Читателю хорошо видно, что сам рассказчик воспринимает свои воспоминания о детстве как счастливые, однако столь же хорошо считываются и другие эмоции: многие эпизоды прокручиваются с мучительным чувством - с болью, сожалением, горечью: каждая новелла - это грустный рассказ о разрушении или утрате чего-то светлого - невинности, чистоты, восторженности, романтичности, мечты. Рассказчик дорожит детскими воспоминаниями, но история детства - это история о потере. И как герой Хэ Чжи-чжана возвращается в «отчий дом», «милую родину» неузнанным, так и во взрослом рассказчике почти невозможно узнать мальчика, героя его собственных воспоминаний.

\section{Персонажи взрослой жизни}

В воспоминаниях о более близком к настоящему времени часто фигурируют все те же друзья детства, выросшие «товарищи по несчастью». В этой части воспоминаний получает развитие мотив маргинального быта, связанный с образом дяди Коли. Истории всех выросших друзей и самого рассказчика наглядно и словно нарочито демонстрируют: причины и мотивы всех поступков кроются в детстве. Одновременно с этим создается ощущение, что у героев Башкуева будто нет сил прожить дольше среднего возраста, словно запас их жизненной энер- 
гии получает брешь в детстве, а затем постепенно выхолащивается и растрачивается попусту: «По сути жизнь сорокалетнего мужчины со всех сторон окружена смертями, причем всегда они преждевременны. Никто не доживает до старости) [Башкеева 2018a: 37-38].

Однажды встретив старого друга, рассказчик удивляется: «Ренат, в отличие от меня, помнил мельчайшие подробности нашего сопливого дворового бытия < ..> Ренат застыл, что муха в янтаре, в том далеком времени, и, как знать, возможно, эта память не давала ему превратиться в законченного бандита» [Башкуев 2019: 294].

Такая цепкость памяти обнаруживает механизм, сходный с комическим романтизмом другого товарища детства - Толика: лишь определенный инфантилизм позволяет «пожилым мальчикам» своего поколения сохранять жизнелюбие и витальные силы.

Наблюдение о спасительном воздействии памяти о детстве относительно Рената справедливо и для самого рассказчика. Оказавшись в СИЗО, тот не предпринимает никаких обычных в его положении, разумных, практических шагов для того, чтобы опровергнуть обвинения, а вместо этого соглашается на первого попавшегося адвоката и взамен выстраивания линии защиты предается воспоминаниям о детстве, провозглашая их «шпаргалкой для оправдательной речи» [Башкуев 2019: 276]. Надо заметить, что и причиной ареста становится неожиданный для самого героя благородный поступок: ожившие детские воспоминания заставляют его попытаться встать «на защиту чести и достоинства) нищей сумасшедшей на вокзальной площади. Дурочка - главный свидетель на присяжном заседании, которое вершится в душе рассказчика по поводу прожитой им жизни: «Я сказал, что требую очной ставки со своим детством» [Башкуев 2019: 286].

В другом произведении Г. Башкуева «Чемодан из Хайлара» (2018) мы видим очень похожих героев: во многом совпадающий рассказчик и окружающие его люди, которые, не научившись жить, много и беспомощно пьют, и действие перемещается все по тем же знакомым локациям: из домов в гаражи, в квартиры товарищей, случайных подруг, в бараки первых встречных, которые всегда согласны разделить бутылку, в наркологическую больницу, наконец, в воспоминания детства.

Наконец, весьма важная группа персонажей повести - женские образы: женщина в цветастом платье, старая девочка Надя, Оля-Пятница, Аленка, подруга Рената Алла, подруга Толика Света-Стелла, проститутка «сестрица Аленушка», городская сумасшедшая и самый безликий женский персонаж - жена. Как было сказано выше, история каждой из них - это словно разложенная на несколько вариаций одна и та же маленькая трагедия продавщицы Инги.

Семья героя - заложники его неразрешенной внутренней драмы, от поведения жены ничего не зависит, потому что герой от нее ничего не ждет. Все ссоры и раздоры - лишь следствие борьбы героя со своими обидами и страхами. В повести нет попыток конструктивного диалога, конфликты в семье не разрешаются, а обрываются: случается стычка, и рассказчик уходит, словно дождавшись подходящего момента, чтобы хлопнуть дверью. Причины такого поведения кроются все в той же инфантильности: «Если Геннадий повздорил с женой, то сразу - щетка, бритва и - вон из дома. Если что не так, то сразу кулачное разбирательство ...» [Башкеева 2018а: 38-39].

Череда случайных встреч и измен завершается обретением кратковременного счастья на протяжении нескольких летних недель на старой даче приятеля с возникшей ниоткуда (вернее, по ошибке жены!) девочкой из снов - Аленкой. Но и оно быстро заканчивается, и именно на вокзале, в момент проводов уезжающей навсегда Аленки, происходит встреча с городской сумасшедшей: рассказчик узнает в ней Ингу, в точности повторившую судьбу дурочки, с которой она когда-то так жестоко обошлась. Два женских образа детства соединяются в один, и под влиянием внезапного рыцарского порыва герой вступается за сумасшедшую Ингу, расплачиваясь за это арестом и заключением.

Проживая свою жизнь, словно плывя по течению (метафора реки возникает в первой же новелле), не удивляясь ни странным просьбам, ни случайным встречам, рассказчик в любой ситуации сохраняет отрешенно-ироничное отношение к происходящему. Однако после кратковременных 
каникул с Аленкой и последовавшей утраты герой словно просыпается и действительно начинает «играть в нападении», как он это декларирует в своих записках и перед следователем. В этом сюжетном повороте видится символическое разрешение комплекса вины рассказчика перед женщиной: герой, как ни парадоксально, словно оживает и просыпается, именно в заключении.

В этом смысле сюжетная структура повести отчасти укладывается в универсальную мифологическую схему: череда зарисовок-событий из жизни рассказчика, выстроенных в своеобразное «мифологическое путешествие» [Воглер 2015], заканчивается обретением «эликсира» - катарсиса. Однако благополучной развязки не случается: суд не оправдывает героя, рассказчик остается в заключении на пять с половиной лет, отбывает большую часть срока, а незадолго до условно-досрочного освобождения не выдерживает и совершает неудачную попытку побега, тем самым продлив срок заключения.

Башкуевский пожилой и злой мальчик, остро рефлексирующий на тему детства и взросления, знаменует собой очень важную и актуальную тему инфантильного героя в бурятской литературе. Очень близки пожилому мальчику лирические герои поэтов Булата Аюшеева (г. p. 1963) и Аркадия Перенова (г. р. 1961) за одним важным исключением: для их героев с юношеским взглядом на мир в их несостоявшемся взрослении не существует конфликта. С героями прозаиков Болота Ширибазарова (г. p. 1977) и Булата Молонова (г. p. 1977) его сближает явная автобиографичность, нежное обращение к детству, однако это писатели младшего поколения, поэтому для их героев не столь актуальна травма взросления в позднесоветский период. Для башкуевского мальчика детство неразрывно связано с городом, дворовой романтикой, и в этом он сходится с лирической героиней поэтессы Елены Жамбаловой (г. р. 1986) - и расходится с героями Ширибазарова и Молонова, с их деревенским детством. В целом можно утверждать, что современная бурятская литература еще и не создала взрослых героев, тогда как инфантильных героев достаточно много, и это, безусловно, является отдельной интересной темой для исследования.

\section{Заключение}

Система персонажей повести «Убить время) — результат авторской стратегии по созданию контекста, формирующего литературный характер. «Схема-предвосхищение» [Чернец 2016б: 10], к которой предварительно можно отнести рассказчика при первом знакомстве, - это герой-маргинал. Однако с каждой последующей новеллой, с каждым очередным воспоминанием героя реализуется «механизм постепенного наращивания» [Гинзбург 1979: 89] проявлений рассказчика в произведении. Мотивные комплексы, связанные с отдельными персонажами или группами персонажей, постепенно формируют образ главного героя «пожилого мальчика».

«Фокусом авторской точки зрения» [Гинзбург 1979: 90], объединяющим, на первый взгляд, разрозненные истории, становится рефлексия по поводу времени. Драмы героев повести происходят на фоне социальной трагедии страны, «экзистенциального коллапса), однако действие повести сосредоточено на бытовом течении жизни, и это намеренно подчеркивается отрешенностью в фиксации событий настоящего времени. Как было справедливо отмечено: «Писатель как бы изгоняет из повести социальные контексты, идеологическую рефлексию, выдвигает на первый план историю человека вообще» [Башкеева 2018a: 37].

Истоки экзистенциального кризиса, охватившего поколение позднесоветской эпохи, автор в конечном счете возводит к тому, что по какой-то причине родители разучились жить и любить и не научили этому своих детей. Воспоминания «пожилого мальчика» содержат горькую обиду своего поколения, и за внешне отстраненным, ироничным образом рассказчика кроется «личное авторское чувство сожаления от того, что частная жизнь отдельного человека оказывается под давлением всего социального, огосударствленного, в огружении мира неуютного, неудобного для нормального человеческого существования» [Имихелова 2018: 6].

Название повести отсылает к сюжетным поворотам - герой убивает время в СИЗО, а до этого ему «нужно было убить время〉 после ссоры с женой. Легко обнаруживаются и другие значения: с одной стороны, своим поведением, образом жиз- 
ни герой убивает «время своей жизни», с другой стороны, совершив благородный поступок, защищая сумасшедшую, он убивает в себе страх, «убинает во времени, как прошедшем, так и текущем, присущие этому времени слабости и недостатки, горечь и зло» [Башкеева 2018а: 39]. Добавим, что

\section{Литература}

Бату даева 2019 - Батудаева Д. Книга-покаяние «самого талантливого автора по прозе и драматургии» вышла в Бурятии // Номер один. 2019. 12 октября. URL: https://gazeta-n1. ru/news/society/79304/ (дата обращения 10.03.2020).

Башкеева 2018а - Баикеева B. B. Между социализмом и капитализмом: драма героя в повести Г. Башкуева «Записки пожилого мальчика» // Вестник Бурятского государственного университета. 2018. № 2-3. С. 35-40

Башкеева 20186 - Баикеева В. В. Драма брошенности в повести Г. Башкуева «Записки пожилого мальчика» («Убить время») // Вестник Бурятского государственного университета. 2018. № 2-4. С. 62-67.

Башкуев 2019 - Баикуев Г. Т. Убить время: повести разных лет. Улан-Удэ: Изд-во ПАО «Республиканская типография», 2019.520 с.

Близняк 2011 - Близняк О. М. Мотивные комплексы как системная характеристика современной русской литературы: на материале творчества А. Барковой, О. Фокиной, Н. Ключаревой: дисс. ... канд. филол. наук. Армавир, 2011. 159 с.

Воглер 2015 - Воглер К. Путешествие писателя. Мифологические структуры в литературе и кино / пер. с англ. М.: Альпина нон-фикшн, $2017.476 \mathrm{c}$.

Гаспаров 1994 - Гаспаров Б. М. Литературныс лейтмотивы. Очерки по русской литературе ХХ века. М.: Наука, Вост. лит., 1994. 304 с.

Гинзбург 1979 - Гинзбург Л. Я. О литературном герое. М.: Советский писатель, 1979. 223 с.

\section{References}

Bashkeeva V. V. Between socialism and capitalism: hero's drama in 'Notes of Elderly Boy' novel by G. Bashkuev. BSU Bulletin. Philosophy. 2018. No. 2-3. Pp. 35-40. (In Russ.)

Bashkeeva V. V. Drama of forsakenness of the hero in story of G. Bashkuev «The Notes of Young Old Man» («To Kill the Time»). BSU Bulletin. Philosophy. 2018. No. 2-4. Pp. 62-67. (In Russ.) формат записок, рефлексия героя и педантичный самоанализ позволяют расширить последнюю трактовку заглавия: «убить время» - значит убить в себе следы конкретной (советской) эпохи, избавиться от страхов и комплексов, стать свободным человеком.

Грязнова 2012 - Грязнова О. Б. Реализация концепта 'Дом/Родина' в прозе Г. Башкуева // Функционально-когнитивный анализ языковых единиц и его аппликативный потенциал: мат-лы І междунар. науч. конф. (г. Барнаул, 5-7 октября 2011 г.). Барнаул: Алтайская гос. пед. академия, 2012. С. 100-102.

Имихелова 2018 - Имихелова С. С. О роли дебюта в творческой судьбе писателя (из опыта создания литературных биографий бурятских писателей) // Вестник Бурятского государственного университета. 2018. № 2-1. C. 3-11.

Саблин, Болячевец, Будацыренова 2017 - Caблин И. В., Болячевеч Л. С., Будауыренова С. Б. Бурят-Монголия онлайн и офлайн: современная литература и историческая память // Неприкосновенный запас. Дебаты о политике и культуре. 2017. № 2 (112). С. 8397.

Силантьев 2004 - Силантьев И. В. Поэтика мотива. М.: Языки славянской культуры, 2004. 296 c.

Фрейденберг 1988 - Фрейденберг О. М. Система литературного сюжета // Монтаж. (литература, искусство, театр, кино). Сб. Сост. М. Б. Ямпольский. М.: Наука, 1988. С 216236.

Чернец 2016а - Чернец Л. В. О типологическом изучении литературных персонажей // Stephanos. 2016. № 1 (15). C. 80-90.

Чернец 2016 - Чернеч Л. В. Тип персонажа и его эволюция // Вестник Московского городского педагогического университета. Серия: Филология. Теория языка. Языковое образование. 2016. № 4 (24). С. 8-16.

Bashkuev G. T. To Kill Time: Novels of Various Years. Ulan-Ude: Respublikanskaya Tipografiya, 2019.520 p. (In Russ.)

Batudaeva D. A repentance book by 'the most talented prose and drama author' published in Buryatia. On: Nomer Odin (online media outlet and newspaper). 2019, October 12. Available at: https://gazeta-n1.ru/news/society/79304/ (accessed: March 10, 2020). (In Russ.) 
Bliznyak O. M. Complexes of Motifs as a System Characteristic for Modern Russian Literature: A Case Study of Works by A. Barkova, O. Fokina, N. Klyuchareva. Cand. Sc. (philology) thesis. Armavir, 2011. 159 p. (In Russ.)

Chernets L. V. The personage type and its evolution. Moscow City University Vestnik. Series: Philology. Theory of Linguistics. Linguistic Education. 2016. No. 4 (24). Pp. 8-16. (In Russ.)

Chernets L. V. Typological research of literary characters revisited. Stephanos. 2016. No. 1 (15). Pp. 80-90. (In Russ.)

Freydenberg O. M. Literary plot system. In: Yampolsky M. B. (comp.) The Montage (Literature. Arts, Theatre, Cinema). Collected Papers. Moscow: Nauka, 1988. Pp. 216-236. (In Russ.)

Gasparov B. M. Literary Leitmotifs: Essays on $20^{\text {th }}$-Century Russian Literature. Moscow: Nauka - Vostochnaya Literatura, 1994. 304 p. (In Russ.)

Ginzburg L. Ya. About a Key Literary Character. Moscow: Sovetskiy Pisatel', 1979. 223 p. (In Russ.)
Gryaznova O. B. Implementation of the concept 'home/Motherland' in G. Bashkuev's prose. In: Functional and Cognitive Analysis of Language Units and Its Applicative Potential. Conference Proceedings (Barnaul; October 5-7, 2011). Barnaul: Altay State Pedagogical Academy. 2012. Pp. 100-102. (In Russ.)

Imikhelova S. S. On role of debut in writer's creative destiny (from the experience of creating the first literary biographies of Buryat writers). BSU Bulletin. Philosophy. 2018. No. 2-1. Pp. 3-11. (In Russ.)

Sablin I. V., Bolyachevets L. S., Budatsyrenova S. B. Buryat-Mongolia online and offline: contemporary literature and historical memory. Neprikosnovennyy zapas. Debaty o politike i kul'ture. 2017. No. 2 (112). Pp. 83-97. (In Russ.)

Silantyev I. V. Poetics of Motif. Moscow: Yazyki Slavyanskoy Kultury, 2004. 296 p. (In Russ.)

Vogler C. The Writer's Journey: Mythic Structure for Writers. Moscow: Alpina Non-Fikshn, 2017. 476 p. (In Russ.) 